\title{
Mature pomegranate recognition methods in natural environments using machine vision
}

\author{
Xiangxiao Lei ${ }^{1,2}$ (1) Honglin Ouyang ${ }^{1}$ Lijuan $\mathrm{Xu}^{{ }^{2 *}}$ \\ ${ }^{1}$ College of Electrical and Information Engineering, Hunan University, Changsha, Hunan, 410082, China. \\ ${ }^{2}$ Changsha Social Work College, 410004, Changsha, Hunan, China. E-mail: 306400605@qq.com. "Corresponding author.
}

ABSTRACT: The use of machine vision to recognize mature pomegranates in natural environments is of major significance in improving the applicability and work efficiency of picking robots. By analyzing the color characteristics of color images of mature pomegranates under different illumination conditions, the feasibility of the $\mathrm{YCbCr}$ color model for pomegranate image recognition under different illumination conditions was proven. First, the Cr component map of pomegranate image is selected and then the pomegranate fruit is segmented by the kernel fuzzy C-means clustering algorithm to obtain the pomegranate image. Contrast experiments of pomegranate image segmentation under different illumination conditions were then performed using the proposed kernel fuzzy C-means clustering algorithm, the fuzzy C-means clustering algorithm, the Otsu algorithm and the threshold segmentation algorithm. Results of the experiments verified the effectiveness and superiority of the proposed algorithm.

Key words: Punica granatum L., machine vision, fuzzy clustering, kernel, image segmentation. Métodos de reconhecimento de romã madura em ambientes
naturais usando visão de máquina

RESUMO: O uso de máquina para reconhecer romãs maduras em ambientes naturais é de grande importância para melhorar a aplicabilidade e a eficiência do trabalho de robôs de colheita. Ao analisar as características de cor das imagens coloridas de romãs maduras sob diferentes condições de iluminação, a viabilidade do modelo de cores YCbCr para o reconhecimento de imagens de romãs sob diferentes condições de iluminação foi comprovada. Primeiro, o mapa do componente $\mathrm{Cr}$ da imagem da romã é selecionado e, em seguida, o fruto da romãzeira é segmentado pelo algoritmo de agrupamento $C$-means fuzzy do kernel para obter a imagem da romã. Experimentos contrastados de segmentação de imagens de romã sob diferentes condições de iluminação foram então realizados usando o algoritmo proposto de agrupamento C-means fuzzy, o algoritmo fuzzy de agrupamento C-means, o algoritmo Otsu e o algoritmo de segmentação de limiares. Os resultados dos experimentos verificaram a efetividade e superioridade do algoritmo proposto.

Palavras-chave: Punica granatum L., visão de máquina, agrupamento fuzzy, kernel, segmentação de imagens.

\section{INTRODUCTION}

With rising labor costs, rapid development of intelligent control technology and information technology, and increasing processing speed of computers, studies on fruit and vegetable picking robots have attracted more and more attention. Among them, the picking robots based on machine vision have become a research focal point in both domestic and foreign agriculture engineering fields (WANG et al, 2015; XIONG et al, 2017; ZHAO et al,2016; BULANON \& KATAOKA T, 2010). The prerequisite for the proper operation of any picking robot is to achieve the correct identification and the position of the fruit. In order to correctly identify the fruit, the key is to separate the fruit from complex backgrounds such as those containing branches and leaves under complex lighting conditions. Therefore, determination of the exact spatial location of the fruit is necessary for the robot to complete fruit picking.

In order to improve the accuracy of fruit recognition, domestic and foreign scholars have carried out a significant volume of research. In the literature (XIONG et al, 2017), the I component map of the nighttime litchi image was selected and the Otus algorithm was used to segment the image and remove the background. The fuzzy C-means (FCM) clustering algorithm was used to obtain the nighttime litchi fruit image. One study (JI et al. 2016) proposed a Retinex algorithm based on a guided filter for nighttime apple image enhancement and this achieved certain results. Another study (JIA et al., 2015) employed the particle swarm optimization algorithm-based independent component analysis and 
night noise reduction algorithm to achieve nighttime recognition for an apple picking robot.

Based on the color information in the images, the localization and recognition system of grapes in the natural environment was studied (REIS et al., 2012). XU et al. (2005) studied the citrus recognition method based on color information. XIONG et al. (2011), identified lychee fruits and fruit stalks by selecting the $\mathrm{Cr}$ component map in the $\mathrm{YCbCr}$ color model of the lychee image, combined with one-dimensional random signal histogram and fuzzy C-means clustering algorithm. The above studies provided a good theoretical basis for the operation of picking robots. However, the above studies were more focused on daytime front-lighting and backlighting conditions, with little or no involvement in nighttime and daytime insufficient illumination conditions. While more attention has been paid to the picking of apples, lychees, grapes, citrus and other fruits, the pomegranate has hardly been studied.

As a proven unsupervised clustering analysis method, the FCM clustering algorithm can retain more information from the original image. Therefore, it has been widely used in areas such as medical image processing (ZENG et al., 2008), pattern classification (YANG \& HUANG, 2015), and fruit image segmentation (XIONG et al., 2017; XIONG et al., 2011; BETANZOSA et al., 2000). However, the standard FCM clustering algorithm does not fully consider the spatial information of the pixels and; is therefore, sensitive to the noise information in the image (CHUANG et al., 2006).

In order to improve the robustness of the FCM clustering algorithm, many researchers have introduced the kernel method into various clustering algorithms (YU et al., 2015; KANG et al., 2010; MA et al., 2007; GONG et al., 2013; ZHANG \& LI, 2017; LEI \& OUYANG, 2018; CHAIRA \& RAY, 2005). The fundamental concept is to map each sample to the high-dimensional kernel space by using nonlinear mapping. The nonlinear problem in the input space is linearized in the high-dimensional feature space (BETANZOSA et al., 2000), thus improving the performance of the clustering algorithms.

In this paper, we selected mature pomegranates as a subject and analyze the RGB, LAB, and $\mathrm{YCbCr}$ color models of pomegranate images under different illumination conditions. By selecting the $\mathrm{Cr}$ component map in $\mathrm{YCbCr}$ color model, the improved kernel fuzzy C-means clustering algorithm (KFCM) is adopted to recognize pomegranate images under sufficient daytime illumination, insufficient daytime illumination, and nighttime conditions.

\section{MATERIALS AND METHODS}

\section{Image acquisition and color feature analysis Color image acquisition}

This paper used mature pomegranates as research subjects and studied the recognition of mature pomegranates in the natural environment. The image collection times were from 10:00 to 11:00 in the morning, from 18:30 to 19:30 in the afternoon and from 20:00 to 21:00 in the evening on September 6 to 12,2018 . More than 400 images were collected, including 212 from 9:00 to 11:00, 120 from 18:00 to 19:30 and 93 from 20:00 to 21:30.

The machine vision system included a CCD camera, an image acquisition card, and a computer. The DH-HV3100FC digital camera was used, the image acquisition card was a DH-VT123, the resolution of acquired visible light image was $1080 \times 1440$ pixels, and the format was 24-bit true color image in JPG format. The image was adjusted to $256 \times 256$ pixels before applying the algorithms. Experimental platform: The computer used was the Intel(R) Core(TM) i53230M CPU@2.60 GHz, configured with 4 GB memory. The operating system was Windows 10, and the programming language was MATLAB (2014R).

\section{Color feature analysis}

Comparing figure 1(a), figure 1(b) and figure 1(c), it can be seen that the color of the pomegranate fruits in the pomegranate images is relatively vivid; however, there are a lot of dark areas in the image background, and the clarity of the whole image is not high. The edges are relatively blurred. When the daytime illumination is insufficient, the dark areas in the background are less than the nighttime; however, the color of the fruit is not as clear as that observed at nighttime. There are shadows, and the edges are also blurred. During the shooting in natural conditions, the background of the acquired images is complex and variable, making it difficult to accurately extract the pomegranate fruit.

In this paper, various color models (RGB, LAB, YCbCr, YIQ, HSV) were used to analyze the color features of pomegranate images collected under natural conditions. Figure 2 shows the 15 color component images of pomegranate images taken during daytime with sufficient illumination. Among the 15 color components, the fruit and the background have a large contrast in the images of the A component, the $\mathrm{Cr}$ component, the I component, and the $\mathrm{H}$ component. Thus, these four components can be selected for analysis of the pomegranate image under sufficient daytime illumination. 


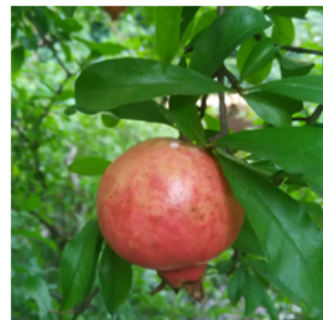

(a)

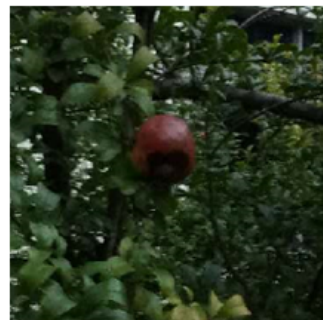

(b)

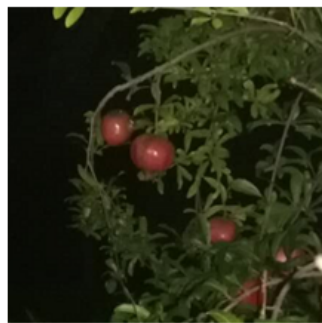

(c)

Figure 1 - Daytime and nighttime pomegranate images.

a) Daytime -- sufficient illumination; (b) Daytime -- insufficient illumination; (c) Nighttime
conditions.

In the same way, the 15 color components analysis was performed on the pomegranate images taken when the daytime illumination was insufficient. It was reported that in the images of the A component, the $\mathrm{Cr}$ component, and the $\mathrm{H}$ component there was a relatively large contrast between the fruit and the background. These three components can be selected to analyze the pomegranate images with insufficient daytime illumination.

Under night conditions, 15 analyzes of color components were also performed on pomegranate images. It was reported that the fruit and the background had relatively large contrast in the images of the A component, the Cr component, the I component, and the H component. Consequently, these four components can be selected to analyze the pomegranate image under nighttime flash conditions.

In summary, the $\mathrm{Cr}$ component image and the A component image provided better suppression of the effects of the sky background and uneven light in the analysis of the color characteristics of the pomegranate images with sufficient daytime illumination, insufficient daytime illumination and nighttime conditions. From the real-time consideration of the algorithm, the conversion of the RGB color model to the Lab color model is nonlinear while the conversion of the RGB color model to the $\mathrm{YCbCr}$ model is linear. Hence, the $\mathrm{YCbCr}$ color model was finally selected for pomegranate image segmentation. The conversion formula from the RGB color model to the $\mathrm{YCbCr}$ model is

$Y=0.299 R+0.578 G+0.114 B$

$\{b=-0.1687 R-0.3313 G+0.5 B+0.5$

$C r=0.53 R-0.4187 G-0.0813 B+0.5$

Kernel fuzzy C-means clustering algorithm

\section{Fuzzy C-means clustering algorithm}

The classical FCM clustering algorithm iteratively optimizes the objective function based on the weighted similarity measure of image pixels and the cluster centers to obtain the minimum value of the objective function and determine the optimal cluster. The objective function of the FCM algorithm is usuallv expressed as follows:

$J(u, v)=\sum_{i=1}^{N} \sum_{j=1}^{c} u_{i j}^{m}\left\|x_{i}-v_{j}\right\|^{2}$

where $\mathrm{m}$ is the weighting factor (Fuzzy coefficient). Note that $1<m<\infty$. In this paper, $\mathrm{m}=2 ; u_{i j}$ indicates the membership degree of the i-th sample belonging to the $\mathrm{j}$-th class, $\sum_{j=1}^{c} u_{i j}-1 u_{u_{i j} \in[0,1]}, 1 \leq \mathrm{i} \leq \mathrm{N} ; \mathrm{X}_{i}$ indicates the $\mathrm{i}$-th sample, $V_{j}$ indicates the $\mathrm{jth}$ clustering center, $\left\|x_{i}-v_{j}\right\|$ is the distance norm between the sample $\mathrm{X}_{i}$ and the cluster center $\mathrm{V}_{j}$. Euclidean distance is used in this paper. The iterative formulas for the fuzzy membership degree $\mathrm{U}_{i j}$ and the cluster center $\mathrm{V}_{j}$ can be obtained by using the Lagrangian conditional extreme value optimization theory.

$u_{i j}=\left[\sum_{k=1}^{c}\left(\frac{\left\|x_{i}-v_{j}\right\|^{2}}{\left\|x_{i}-v_{k}\right\|^{2}}\right)\right]^{-1}$

$\mathrm{v}_{j}=\frac{\sum_{i=1}^{N} u_{i j}^{2} x_{i}}{\sum_{i=1}^{N} u_{i j}^{2}}$

Kernel fuzzy C-means clustering algorithm

Using the kernel method, the objective function of KFCM is

$J=\sum_{i=1}^{N} \sum_{j=1}^{C} u_{i j}^{m} \| \phi\left(x_{i}\right)-\left.\phi\left(v_{j}\right)\right|^{2}$

Defined by the Mercer core

$d^{2}\left(x_{i}, v_{j}\right)=\left|\phi\left(x_{i}\right)-\phi\left(v_{j}\right)\right|^{2}=K\left(x_{i}, x_{i}\right)+K\left(v_{j}, v_{j}\right)-2 K\left(x_{i}, v_{j}\right)$

Ciência Rural, v.49, n.9, 2019. 


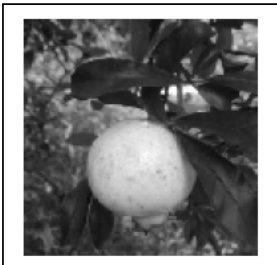

(a) RGB R component

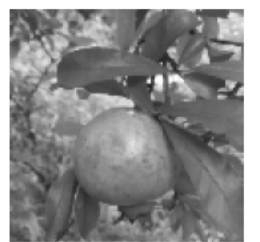

(d) LAB L component

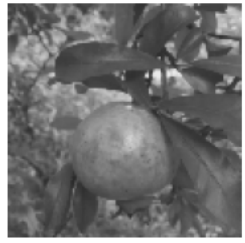

(g) $\mathrm{YCbCr} \mathrm{Y}$ component (h) $\mathrm{YCbCr} \mathrm{Cb}$ component (i) $\mathrm{YCbCr} \mathrm{Cr}$ component

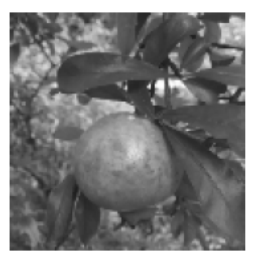

(j)YIQ Y component

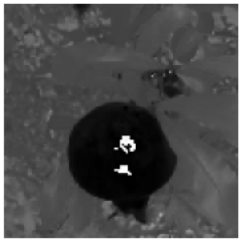

(m) HSV H component

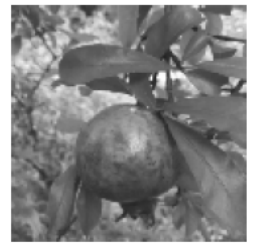

(b) RGB G component

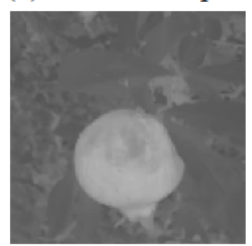

(e) LAB A component
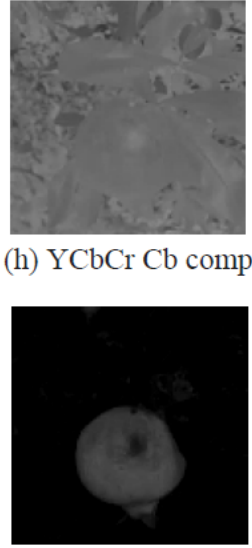

(k)YIQ I component

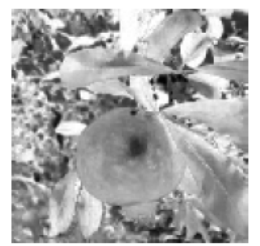

(n) HSV S component
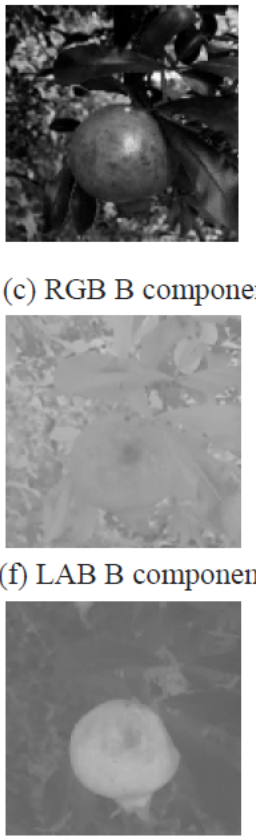

(c) RGB B component

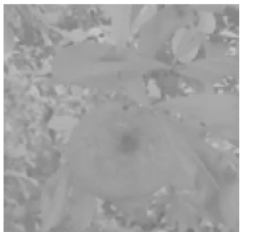

(f) LAB B component

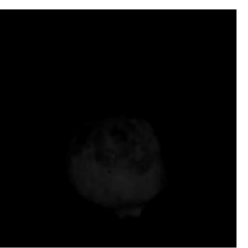

(1) YIQ Q component

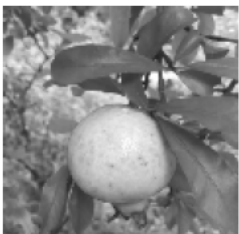

(o) HSV V component

Figure 2 - Single fruit image under different color components with sufficient daytime illumination.

Using the Gaussian kernel function, we have $\mathrm{K}(\mathrm{x}, \mathrm{x})=1$. Then, equation (6) can be rewritten as $d^{2}\left(x_{i}, v_{j}\right)=\left\|\phi\left(x_{i}\right)-\phi\left(v_{j}\right)\right\|^{2}=2-2 K\left(x_{i}, v_{j}\right)$

Apply (7) to (5), the objective function of the KFCM algorithm can be obtained as

$$
J=2 \sum_{i=1}^{N} \sum_{j=1}^{C} u_{i j}^{* m}\left(1-K\left(x_{i}, v_{j}\right)\right)
$$

By finding the optimal solution to equation (8), we can derive the iterative formulae for obtaining the membership degree $u_{i j}^{*}$ and the cluster center $v_{j}^{*}$

$$
\begin{aligned}
& u_{\dot{\varphi}}^{\circ}=\left(\frac{\left(1-K\left(x_{i}, v_{j}\right)\right)^{\frac{1}{c}}}{\sum_{j=1}^{c}\left(1-K\left(x_{t}, v_{f}\right)\right)^{\frac{1}{n-1}}}\right)^{-1} \\
& \mid v_{j}^{*}=\frac{\sum_{j=1}^{N} u_{i j}^{*} x_{j}}{\sum_{j=1}^{N} u_{i j}^{*}}
\end{aligned}
$$

The corresponding iterative calculation of the KFCM algorithm is described below.

Step 1: Based on prior knowledge, set the iteration stop threshold $\varepsilon$, the maximum number 
of iterations $\mathrm{t}_{\max }$, initialize the membership degree matrix $U$ and the iteration counter $\mathrm{t}=0$;

Step 2: Calculate the fuzzy cluster center using formula (10);

Step 3: Calculate the new membership degree matrix using equation (9);

Step 4: If $\left\|\mathrm{U}^{\mathrm{t}}-U^{(t-1)}\right\|<\varepsilon$ or $\mathrm{v}^{\mathrm{t}}=\mathrm{v}^{\mathrm{t}+1} \mathrm{t}>\mathrm{t}_{\max }$ the iteration ends, output $U$ and $V$; otherwise $t=t+1$, return to Step 2 and continue with the iteration.

In this paper $\varepsilon=0.001, \mathrm{t}^{\max }=100, \mathrm{~m}=2$.

\section{RESULTS AND DISCUSSION}

To verify the accuracy of the proposed kernel fuzzy $\mathrm{C}$-means clustering algorithm for pomegranate image recognition, image recognition experiments for daytime and nighttime conditions were conducted. Subsequently, 150 sufficient daytime illumination, 100 insufficient daytime illumination, and 80 nighttime LED illumination images were randomly selected (Table 1).

\section{Recognition test for a pomegranate fruit}

The fruit identified by the algorithm in the study was a pomegranate. The test results are shown in table 1. The standard for the identification of pomegranate fruit images is for more than $90 \%$ of all pomegranate fruit images to be identified correctly.

The test results in table 1 show that the algorithm can correctly identify mature pomegranates in a natural environment. Using the same algorithm to identify pomegranate under various lighting conditions leads to different results. The recognition capability is better at night than during the day. The recognition capability is better with sufficient daytime illumination than with a lack of illumination. The reasons are sufficient daytime illumination, insufficient
Table 1 - Results of the pomegranate recognition experiment.

\begin{tabular}{lccc}
\hline $\begin{array}{l}\text { illumination } \\
\text { condition }\end{array}$ & $\begin{array}{c}\text { number of } \\
\text { images }\end{array}$ & $\begin{array}{c}\text { correct } \\
\text { number }\end{array}$ & $\begin{array}{c}\text { accuracy } \\
\text { rate/\% }\end{array}$ \\
\hline $\begin{array}{l}\text { Sufficient } \\
\text { daytime }\end{array}$ & 150 & 136 & 90.67 \\
$\begin{array}{l}\text { Relatively } \\
\text { insufficient } \\
\text { daytime }\end{array}$ & 100 & 85 & 85 \\
$\begin{array}{l}\text { Night time } \\
\text { Total }\end{array}$ & 80 & 77 & 96.25 \\
\hline
\end{tabular}

illumination, among others. The fruit under the backlight is black, which is close to the background color, affecting the accuracy of the pomegranate image recognition. Under night conditions, the illuminated mature pomegranate can be clearly distinguished from the background, and there is no backlight acquisition image, which effectively improves the success rate of the recognition. However, under night conditions, an external light source in the background of the image would cause an identification error for the pomegranate image.

\section{Analysis of algorithms}

For comparison, the threshold segmentation algorithm, the Otsu algorithm, and the FCM clustering algorithm were compared with the KFCM clustering algorithm proposed in this paper, and the segmentation effect diagram is shown in figure $3,4,5$.

It can be seen from figures $3,4,5$ that the FCM algorithm cannot segment the pomegranate image under insufficient daytime illumination while

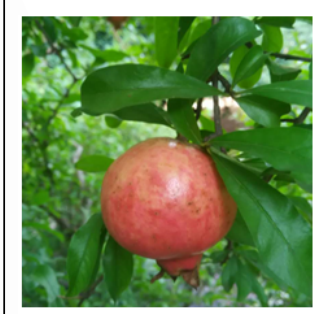

(a)

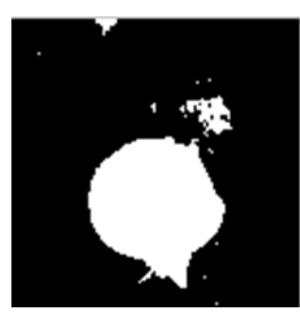

(b)

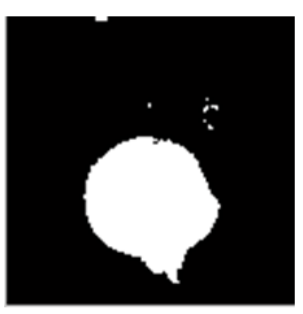

(c)

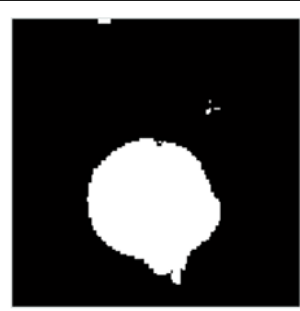

(d)

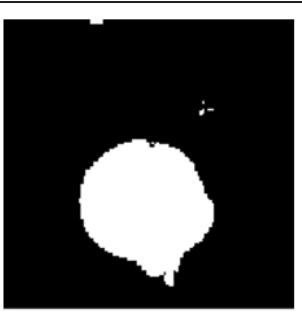

(e)

Figure 3 - Segmentation effect of full illumination image.

(a) Original image; (b) Threshold segmentation; (c) Otsu segmentation; (d) FCM segmentation; (e) KFCM segmentation. 


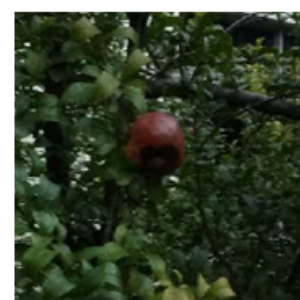

(a)

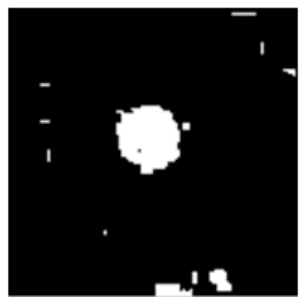

(b)

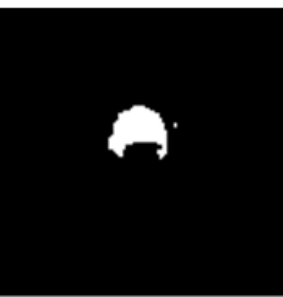

(c)

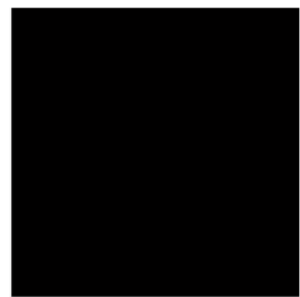

(d)

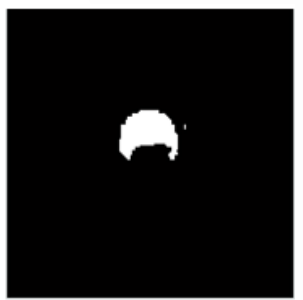

(e)

Figure 4 - Segmentation effect of insufficient illumination image.

(a) Original image; (b) Threshold segmentation; (c) Otsu segmentation; (d) FCM segmentation; (e) KFCM segmentation.

the KFCM, Otsu, and threshold segmentation methods can segment the pomegranate image. However, the segmentation effect of the threshold segmentation method is poor. For a single pomegranate image with sufficient daytime illumination and nighttime multiple pomegranates image, the KFCM, FCM, Otsu, and threshold segmentation algorithms can accurately segment the pomegranate from the background image. The segmentation effect of the threshold segmentation algorithm is relatively inferior, and a large number of background items are recognized as pomegranates, resulting in the largest area of misidentification. Compared with the FCM and Otsu algorithms, the KFCM algorithm involves mapping each sample to the high-dimensional kernel space using a nonlinear method. The nonlinear problem in the input space is linearized in the high-dimensional feature space; the potential noise in the image is effectively suppressed, thus improving the performance of the clustering algorithms. The KFCM algorithm has the largest segmented area and the most complete pomegranate image for pomegranate images with sufficient daytime illumination, relatively insufficient daytime illumination and nighttime conditions.

Segmentation times (running times) of the KFCM, FCM, Otsu, and threshold segmentation algorithms for a single pomegranate image with sufficient daytime illumination, a single pomegranate image with insufficient daytime illumination, and for multiple pomegranate images with nighttime conditions, are shown in table 2.

It can be seen from table 2 that for pomegranate images with sufficient daytime illumination and nighttime conditions, the FCM and Otsu algorithms have the longest running time, the threshold segmentation method was faster, and the KFCM algorithm was the fastest of the four algorithms. The KFCM algorithm takes slightly

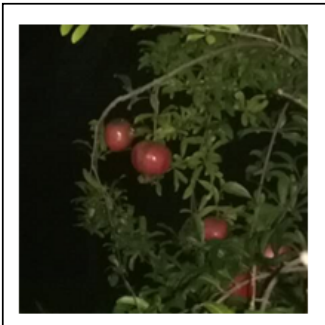

(a)

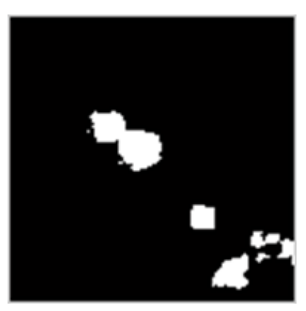

(b)

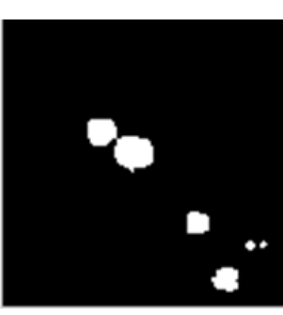

(c)

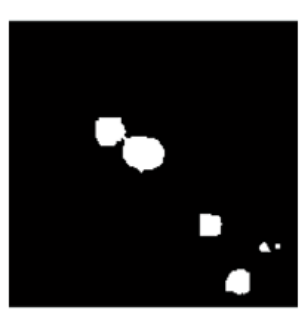

(d)

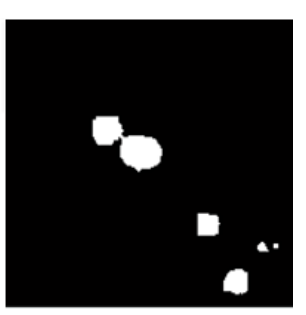

(e)

Figure 5 - Segmentation effect of nighttime image.

(a) Original image; (b) Threshold segmentation; (c) Otsu segmentation; (d) FCM segmentation; (e) KFCM segmentation. 
Table 2 - Comparison of running time for different algorithms.

\begin{tabular}{|c|c|c|c|c|}
\hline \multirow[t]{2}{*}{ Image } & \multirow[b]{2}{*}{ Threshold segmentation } & \multirow{2}{*}{$\frac{\text { time }}{\text { Otsu }}$} & \multirow[b]{2}{*}{ FCM } & \multirow[b]{2}{*}{ KFCM } \\
\hline & & & & \\
\hline Sufficient daytime illumination & 0.134 & 0.165 & 0.056 & 0.048 \\
\hline Relatively insufficient daytime illumination & 0.125 & 0.162 & ------ & 0.187 \\
\hline Nighttime & 0.123 & 0.154 & 0.157 & 0.086 \\
\hline
\end{tabular}

Note: The times in the table are the average running times of 20 experiments.

more time to segment the pomegranate images with relatively insufficient daylight illumination.

\section{CONCLUSION}

In order to quickly and accurately identify fruit images used to guide the operation of fruit picking robots, this paper first converts the color image of pomegranate from RGB color model to $\mathrm{YCbCr}$ model, extracts the $\mathrm{Cr}$ component in $\mathrm{YCbCr}$ model and applies it to image recognition. Secondly, based on the FCM algorithm, the kernel function is introduced and the KFCM clustering algorithm is applied to the segmentation of pomegranate images. The recognition experiments for pomegranate images under various illumination conditions are performed using this algorithm. Results demonstrated that the recognition accuracy is $90.3 \%$. Results also showd that the algorithm achieves a good real-time performance in terms of pomegranate image recognition. The average segmentation of a pomegranate image takes $0.048 \mathrm{~s}$ in sufficient daytime, $0.187 \mathrm{~s}$ in relatively insufficient daytime, and $0.086 \mathrm{~s}$ in nighttime.

\section{DECLARATION OF CONFLICT OF} INTERESTS

The authors declare no conflict of interest. The founding sponsors had no role in the design of the study; in the collection, analyses, or interpretation of data; in the writing of the manuscript, and in the decision to publish the results.

\section{AUTHORS' CONTRIBUTIONS}

All authors contributed equally for the conception and writing of the manuscript. All authors critically revised the manuscript and approved of the final version.

\section{REFERENCES}

BULANON D. M.; KATAOKA, T. Fruit detection system and an end effector for robotic harvesting of Fuji apples [J]. Agricultural
Engineering International: the CIGR Journal, 2010,12(1):203210. Available from: $<$ http://libdb.csu.edu.cn/rwt/SPISCHOLAR/ http/P75YPLUDNFUYE4UQPW3G6ZLMF3YYE3D/index.php/ Ejounral/article/view/1285>. Accessed: Oct. 09, 2017. doi: 1285.

BETANZOSA A. A; et al. Analysis and evaluation of hard and fuzzy clustering segmentation techniques in burned patient images [J]. Image and Vision Computing, 2000, 18(13):1045-1054. Available from: <http://libdb.csu.edu.cn/rwt/SPISCHOLAR/https/ P75YPLUUMNVXK5UDMWTGT6UFMN4C6Z5QNF/science/ article/pii/S0262885600000457>. Accessed: Oct. 09, 2017. doi: 10.1016/s0262-8856(00)00045-7.

CHAIRA, T.,; RAY, A. Fuzzy mearsures for color image retrieval [J/OL]. Fuzzy Sets and Systems, 2005, 150(3):545-560[201510-18]. Available from: <http://http://dx.doi.org/10.1016/j. fss.2004.09.003>. Accessed: Jan. 19, 2017. doi: 10.1016/j. fss.2004.09.003.

CHUANG, K. S.; et al. Fuzzy C-means clustering with spatial information for image segmentation [J]. Computerized Medical Imaging and Graphics, 2006, (30):915. Available from: <http://libdb.csu.edu.cn/rwt/SPISCHOLAR/https/ P75YPLUUMNVXK5UDMWTGT6UFMN4C6Z5QNF/science/ article/pii/S0895611105000923>. Accessed: Oct. 09, 2017. doi: 10.1016/j.compmedimag.2005.10.001.

GONG, M.; et al. Fuzzy C-means clustering with local information and kernel metric for image segmentation [J]. IEEE Transactions on Image Processing, 2013, 22 (2):573-584. Available from: <http://10.1109/TIP.2012.2219547>. Accessed: Nov. 09, 2017. doi: 10.1109/TIP.2012.2219547.

JI, W.; et al. Edge-preserving Retinex enhancement algorithm of night vision image for apple harvesting robot [J]. Transactions of the Chinese Society of Agricultural Engineering, 2016, 32(6):189-196. Available from: <http://kns.cnki.net/kns/detail/ detail.aspx FileName $=$ NY GU201606026\&DbName $=\mathrm{CJ}$ FQ2016>. Accessed: Dec. 12, 2017. doi: 10.11975/j.issn.10026819.2016.06.026.

JIA, W., et al. De-noising algorithm of night vision image for apple harvesting robot $[\mathrm{J}]$. Transactions of the Chinese Society of Agricultural Engineering, 2015, 31(10):219-226. Available from: $<$ http://kns.cnki.net/kns/detail/detail.aspx?FileName=NYG U201510029\&DbName=CJFQ2015>. Accessed: Dec. 12, 2017. doi: 10.11975/j.issn.1002-6819.2015.10.029.

KANG, J., et al. Kernelized fuzzy C-menas clustering algorithm and its application [J]. Chinese Journal of Scientific Instrument,

Ciência Rural, v.49, n.9, 2019. 
2010, 31(7):1657-1663. Available from: <http://kns.cnki.net/ $\mathrm{kns} /$ detail/detail.aspx?FileName $=$ YQXB201007038\&DbNam $\mathrm{e}=\mathrm{CJFQ2010}>$. Accessed: Dec. 12, 2017. doi: 10.19650/j.cnki. cjsi.2010.07.036.

LEI, X.; OUYANG, H. "Image segmentation algorithm based on improved fuzzy clustering," Cluster Comput., 62(1), 1-11 (2018). Available from: $<$ https://link.springer.com/article/10.1007 \%2Fs10586-018-2128-9>. Accessed: Jun. 12, 2018. doi: 10.1007/ s10586-018-2128-9.

MA, B., et al. Kernel clustering-based discriminant analysis [J]. Pattern Recognition, 2007, (40):324-327. Available from: $<$ http://libdb.csu.edu.cn/rwt/SPISCHOLAR/https/ P75YPLUUMNVXK5UDMWTGT6UFMN4C6Z5QNF/science/ article/pii/S0031320306002615>. Accessed: Jan. 12, 2018. doi: 10.1016/j.patcog.2006.05.033.

REIS, M. J. S., et al. Automatic detection of bunches of grapes in natural environment from color images [J]. Journal of Applied Logic, 2012, 10(4):285-290. Available from: $<$ http://libdb.csu.edu.cn/rwt/SPISCHOLAR/https/ P75YPLUUMNVXK5UDMWTGT6UFMN4C6Z5QNF/science/ article/pii/S1570868312000535>. Accessed: Jan. 12, 2018. doi: 10.1016/j.jal.2012.07.004.

WANG, D., et al. Localization method of picking point of apple target based on smoothing contour symmetry axis algorithm [J]. Transactions of the Chinese Society of Agricultural Engineering, 2015, 31(5):167-174. Available from: <http://kns. cnki.net $/ \mathrm{kns} /$ detail/detail.aspx ?FileName $=$ NYGU201505024\& DbName $=$ CJFQ2015 $>$. Accessed: Sep. 12, 2017. doi: 10.3969/j. issn.1002-6819.2015.05.024.

$\mathrm{XU}, \mathrm{H}$., et al. Identification of citrus fruit in a tree canopy using color information $[\mathrm{J}]$. Transactions of the Chinese Society of Agricultural Engineering, 2005, 21(5):98-101. Available from: $<$ http://kns.cnki.net/kns/detail/detail.aspx?FileName $=$ NYGU20 0505023\&DbName $=$ CJFQ2005 $>$. Accessed: Dec. 15, 2017. doi: 10.3321/j.issn:1002-6819.2005.05.023.

XIONG, J., et al. Recognition of Mature Litchi in Natural Environment Based on Machine Vision [J]. Transactions of the Chinese Society for Agricultural, 2011, 42(09):162-166. Available from: <http://kns.cnki.net/kns/detail/detail.aspx?FileN ame $=$ NYJX201109034\&DbName $=$ CJFQ2011 $>$. Accessed: Dec. 12, 2017. doi: 10.3969/j.issn.1000-1298.2011.09.032.

XIONG, J., et al. Visual Technology of Picking Robot to Detect Litchi at Nighttime under Natural Environment [J]. Transactions of the Chinese Society for Agricultural Machinery, 2017, 48(11):2834. Available from: $<\mathrm{http}: / /$ kns.cnki.net/kns/detail/detail.aspx?FileN ame=NYJX201711004\&DbName=CJFQ2017 $>$. Accessed: Jan. 18, 2018. doi: 10.6041/j.issn.1000-1298.2017.11.004.

YANG, X., HUANG, S. Multi-view clustering algorithm based on fuzzy C-means[J]. Journal of Central South University (Science and Technology), 2015, 46(6):2128-2133. Available from: <http://kns.cnki.net/kns/detail/detail.aspx?FileName=ZNG D201506021\&DbName=CJFQ2015>. Accessed: Aug. 23, 2018. doi: $10.11817 /$ j.issn.1672-7207.2015.06.

YU, X., et al. Research on PSO-based intuitionistic fuzzy kernel clustering algorithm[J]. Journal on Communications, 2015, 36(5):74-80. Available from: <http://kns.cnki.net/kns/detail/detail. asp $x$ ? FileName $=$ TXXB201505009\&DbName $=$ CJFQ2015 $>$. Accessed: Aug. 23, 2018. doi: 10.11959/j.issn.1000-436x.2015099.

ZHANG, J.; LI, Z. Kernel-based Algorithm with Weighted Spatial Information Intuitionistic Fuzzy C-means [J]. Journal of Electronics \& Information Technology, 2017, 39(9):2162-2168. Available from: <http://kns.cnki.net/kns/detail/detail.aspx?FileN ame=DZYX201709017\&DbName=CJFQ2017 $>$. Accessed: Aug. 23, 2018. doi: 10.11999/JEIT161317.

ZHAO, Y., et al. A review of key techniques of vision-based control for harvesting robot [J]. Computers and Electronics in Agriculture. 2016, 127:311-323. Available from: <http://libdb.csu.edu.cn/rwt/SPISCHOLAR/https/ P 75 Y PLUUMNVXK 5 UDMWTGT6UFMN4C6Z5QNF/ science/article/pii/S0168169916304227>. Accessed: Aug. 23, 2018. doi: 10.1016/j.compag.2016.06.022.

ZENG, L., et al. Genetic Fuzzy C-Means Clustering Algorithm for Magnetic Resonance Images Segmentation [J]. Journal Of University Of Electronic Science And Technology Of China, 2008, 37(4):627-629. Available from: <http://kns.cnki.net/kns/ detail/detail.asp ? FileName $=$ DKDX200804045\&DbName $=C$ JFQ2008>. Accessed: Jun. 18, 2017. doi: 10.3969/j.issn.10010548.2008.04.040. 